\title{
Chapter 8 \\ Resilience to Climate Stresses in South \\ India: Conservation Responses \\ and Exploitative Reactions
}

\author{
P. Indira Devi, Anu Susan Sam, and Archana Raghavan Sathyan
}

\section{Key Messages}

- State patronage and collective action ensure sustainable management of postdisaster agroecosystems.

- State participation is limited in the case of long-term climate change effects (like water scarcity) as opposed to the case of climate extremes (floods).

- Absence of state presence and collective action leads to resource-depleting practices which are socially, ecologically and financially undesirable.

\subsection{Introduction}

The responses of communities to biotic/abiotic stresses and their ability to adapt, adjust and configure to original or improved positions are largely influenced by their psychological, educational and financial capacities (personal or private attributes), the extent of state support and collective action with community groups (social and public support). However, some of these resilience mechanisms are exploitative and unsustainable in the long run while others are sustainable and improvements over existing ones. The level of social and public support plays a crucial role in adoption

P. Indira Devi $(\varangle)$

Kerala Agricultural University, Thrissur, Kerala, India

e-mail: indiradevi.p@kau.in
A. S. Sam
Regional Agricultural Research Station, Kerala Agricultural University, Kumarakom, Kerala, India
e-mail: anu.susan@kau.in

\author{
A. R. Sathyan \\ College of Agriculture, Kerala Agricultural University, Vellayani, Kerala, India \\ e-mail: archana.rs@kau.in
}


of sustainable practices, as evidenced by the responses of communities to climate change risks.

The Intergovernmental Panel on Climate Change (IPCC) defines resilience as: "the ability of human communities to anticipate, absorb, accommodate and recover from the effects of disturbances" (IPCC, 2012). Though community is considered as an interconnected system, the integration across several disciplines has trailed in the case of community resilience thinking (Cutter, 2016; Hoque et al., 2019). Recently, the need has arisen for the development of a robust resilience assessment tool that can cover various dimensions of community resilience viz. environmental, social, economic, infrastructural and institutional (Cimellaro et al., 2016). Hence, resilience assessments (RAs) have emerged as a key method of understanding human responses to disasters and help them to prepare better strategies to reduce the subsequent negative effects, thus empowering a population that can withstand and adapt to various future disasters (Burton, 2015). Resilient communities are able to avoid or minimize the negative impacts or even gain from the situation. However, it is understood that the resilience mechanisms of individuals and communities differ across regions, nations and societies as impacts also differ in their characteristics across these scales. Understanding the resilience mechanisms and their pros and cons helps to improve and redesign the same to ensure societal acceptance and sustainable development.

We analyse the resilience mechanism to climate change events (floods and droughts) by communities in three different social settings that differ in the level of state intervention and community participation. The situations vary with respect to the nature of shock, level of state intervention and collective action. While two situations are based on the drought-induced water scarcity impacts (long term) where collective action and state intervention is limited, the third is on the management of the impact of severe floods through state participation and collective action. The former leads to exploitative practices and unsustainable resource management and lower social welfare. On the contrary, the latter, where there has been state intervention through farmer collectives, has led to improvement in the fertility status of soils through the ecosystem-based adaptation (EBA) approach, which has produced better yields. Ahmed (2022, Chap. 7 of this volume) documents similar adaptation efforts in Pakistan while Kattel and Nepal (2021, Chap. 11 this volume) in Nepal and Bari et al., (2022, Chap. 12, this volume) in Bangladesh show how technology adoption by communities is helping them build climate resilience.

EBA is defined as combining biodiversity and ecosystem services into an adaptation and development strategy that increases the resilience of ecosystems and communities to climate change through conservation, restoration and sustainable management of ecosystems (Colls et al., 2009). Key benefits of EBA have been identified as securing water resources, ensuring provisional services (food) and buffering people from natural hazards, erosion, and flooding (Munang et al., 2013). An approach that aims at conservation of natural resources through collective action is preferred, as it ensures continuous provision of ecosystem services and welfare. However, such an approach is to be facilitated through technological and financial support and awareness creation among the communities. When the communities are left to market 
forces, the adaptation strategies are prone to be resource exploitative and unsustainable. It may also lead to further reduction in household welfare through financial burden and widening social disparities despite the short-term financial gains.

We depict three case studies: one on the flood management situation in the Kuttanad rice ecosystem (Kerala, Southern India), through active state intervention for EBA and collective action by farmer collectives. The other two case studies are on addressing water scarcity in two agriculturally important districts of Kerala where state's presence is limited, and farmer collectives are not functioning.

\subsection{State Interventions for Resilience to Weather Extremes}

The southern Indian state of Kerala is a narrow strip of land extending from the Western Ghats into the Arabian Sea. Though $14.5 \%$ of the state's land area is prone to floods, the 2018 August floods were the worst in about a century, resulting in the death of 433 persons and destroying infrastructure and livelihood worth USD3.8 billion. Over 65,000 ha of land was inundated and 1259 out of 1664 villages across all the 14 districts of Kerala were affected by the flood (Government of Kerala, 2019).

Kuttanad, the wetland zone situated around the Vembanad Lake spreads across Alappuzha, Kottayam and Pathanamthitta districts of Kerala. Most of the ecosystem is spread over Alappuzha and Kottayam districts, and it is one of the major floodprone areas of the state. The region is very ecologically sensitive, thickly populated and one of the main rice producing tracts in the state spread over $1100 \mathrm{~km}^{2}$ of area in the fertile deltaic region of the five Western Ghats river basins. The paddy farming system in Kuttanad, which is situated 0-3 m below mean sea level, is acknowledged as a Globally Important Agricultural Heritage System by the Food and Agriculture Organisation (FAO) (Koohafkan \& Altieri, ). Farming in Kuttanad is made possible by constructing a series of artificial embankments which prevents saltwater intrusion and flood water entry into the fields. Rice production in this ecosystem is characterized by the presence of strong community institutions, i.e. a collective of farmers who cultivate in the continuous stretch of rice paddies demarcated by manmade earthen bunds (padasekharams) that prevent sea water intrusion. The cultivation is done by the cooperation and collective efforts of the farmer collective (Padasekhara Samithi).

In July 2018, rainfall exceeded the normal levels by $18 \%$ and by mid-July, Kuttanad was flooded. Before the complete withdrawal of flood water from Kuttanad, the second flood in August 2018 hit this region, making the lives miserable. Over 17,300 families lost their houses completely and more than 170,000 houses were partially destroyed. A number of other public and private buildings were destroyed including 1613 schools. Kuttanad's biodiversity, agriculture, animal husbandry, fisheries, infrastructure and water supply systems were also severely affected. As the floods occurred after the sowing of the additional/kharif crop, ${ }^{1}$ the seedlings were

\footnotetext{
${ }^{1}$ Generally, in Kerala rice is grown during three different seasons. First season is virippu (I crop) when the crop is planted in April-May and harvested in August-September. Second season is
} 
completely washed away and the protective bunds that prevented sea water intrusion were destroyed. The estimated loss in Kuttanad was equivalent to $6.6 \%$ of the state's income in 2018.

The state government (State Department of Agriculture Development and Farmer's Welfare) was prepared with a definitive action plan for post-flood recovery strategies and action was initiated immediately, once the floods receded. The action plan was prepared with scientific, technical, and social consultations. The recovery vision for the agriculture sector was to develop sustainable, responsible, integrated, inclusive, eco-friendly and resilient agriculture.

The state's post-flood plan of action was mainly under three strategies: short, medium and long term. Short-term activities addressed the urgent requirements for reinstating agricultural production. Medium- and long-term activities included resilience build up in each subsector through environmentally sustainable integrated farming systems, community-based management of water resources, improvements in the value chain, setting up of early warning systems, and effective communication with enhanced geographic information system and other technology-backed capabilities (Government of Kerala, 2018).

\subsubsection{Short-Term Interventions}

The immediate intervention by the state in this region was to facilitate the replanting of the crop. The strategies involved: confidence-building process among farmers, investing in reconstruction of damaged bunds, soil quality analysis and support mechanism for corrections and farm input supply (seeds, labour, machines, chemical fertilizers and soil ameliorants and organic manures) with technological support and easy access to information. The technological, financial and facilitating role was taken over by the State Department of Agriculture (SDA). The scientific prescription for crop management was developed by the State Agricultural University (SAU).

Local self-governments were also actively involved in the process of rebuilding. The District Disaster Management Authority, which coordinated the rebuilding process repaired and restored the damaged public assets like roads, buildings, flood protection structures like weirs, gates and dykes, coastal protection structures, irrigation and drainage canals and also removed the silt/debris deposits. The Department of Agriculture took the lead to dewater the inundated fields and construct the damaged bunds. This was also supported through the Mahatma Gandhi National Rural Employment Guarantee Programme, which also ensured income to poor households in the area.

mundakan (II crop) and the period is from September-October to December-January. Puncha (III crop) is the third season and it is from December-January to March-April.As Kuttanad is in special ecological zone, the rice cultivation is only in two seasons. First season is known as the additional/kharif crop and season is May-June to August-September. The main crop season is puncha, and it is from October-November to February-March. 
Table 8.1 Soil parameters of Kuttanad during pre- and post-flood periods

\begin{tabular}{l|l|l}
\hline Parameters & Pre-flood status & Post-flood status \\
\hline Soil pH & $3.0-4.0$ & $4.0-5.0$ \\
\hline Organic carbon & $0.97 \%$ & $1.68 \%$ \\
\hline Soil electrical conductivity & $0.2-0.8 \mathrm{dS} / \mathrm{m}$ & $0.02-0.04 \mathrm{dS} / \mathrm{m}$ \\
\hline Phosphorous & $70-100 \mathrm{~kg} / \mathrm{ha}$ & $8-15.0 \mathrm{~kg} / \mathrm{ha}$ \\
\hline Potassium & $350-500 \mathrm{~kg} / \mathrm{ha}$ & $50-100 \mathrm{mg} / \mathrm{kg}$ \\
\hline Calcium & $100-200 \mathrm{mg} / \mathrm{kg}$ & $400-600 \mathrm{mg} / \mathrm{kg}$ \\
\hline Magnesium & $50-60 \mathrm{mg} / \mathrm{kg}$ & $20-30 \mathrm{mg} / \mathrm{kg}$ \\
\hline
\end{tabular}

Source KAU (2019)

Simultaneously arrangements for soil testing were made, and scientific prescriptions were prepared. The silt and sand deposits had resulted in changes in mechanical, physical and chemical properties of the agricultural soils of paddies and created anaerobic conditions. However, silt deposits had also enriched the soil in these stretches with organic matter and certain nutrients that facilitated crop growth. Silt deposition in some areas of upper Kuttanad was up to 4 in. thickness while in lower Kuttanad it was up to 2 in. This silt and clay deposit had major impacts on soil aeration and crop growth.

Details of soil parameters during pre- and post-flood periods are given in Table 8.1. The scientific soil analysis revealed wide variation in the levels of soil nutrients across the regions. There was insufficient amount of some of the macronutrients (phosphorus, potassium, magnesium) and boron (micronutrient) while some of the micronutrients like calcium and zinc content increased in the soil after the flood. The soils of upper Kuttanad became low in organic carbon while it was high in the lower Kuttanad. Heavy metals and pesticide residues were absent, and the $\mathrm{pH}$ level improved and was near neutral.

The Department of Agriculture arranged for the corrections in soil quality (through application of soil ameliorants) and supply of quality seeds (fully subsidized) planting operations were also facilitated and closely monitored by experts (development workers and agricultural scientists). The educational programme focussed on the scientific crop management practices to be followed based on soil test results.

The padasekhara samithis (farmer collectives with members who own/operate within a padasekharams) were provided with $20 \%$ of the total cost of cultivation as advance credit, and the technical information was also provided to them. The Department of Agriculture and SAU were active in monitoring the crop situation as well as educating and supporting the padasekhara samithis.

These interventions have helped in increasing the production $(75 \%)$ by bringing more area under farming (28\%) and improving productivity (see Table 8.2 for details). The average productivity was 6-6.7 t/ha during the pre-flood period (2017-2018) which registered a quantum jump to 8.75-9.4 t/ha, post-flood (2018-2019). The scientific management, monitoring and support that helped to develop community 
Table 8.2 District-wise area, production and productivity of rice in Kuttanad

\begin{tabular}{l|l|l|l|l}
\hline Particulars & \multicolumn{2}{|l|}{ Alappuzha (Puncha rice) } & \multicolumn{2}{l}{ Kottayam (Puncha rice) } \\
\hline Period (year) & $2017-2018$ & $2018-2019$ & $2017-2018$ & $2018-2019$ \\
\hline Area (ha) & 24,000 & 28,800 & 6868 & 10,646 \\
\hline $\begin{array}{l}\text { Production } \\
\text { (tonnes) }\end{array}$ & 115,000 & 191,000 & 34,000 & 71,000 \\
\hline $\begin{array}{l}\text { Productivity } \\
\text { tonnes/ha) }\end{array}$ & 4.79 & 6.63 & 5.0 & 6.7 \\
\hline
\end{tabular}

Source KAU (2019)

resilience facilitated this. The management of deposited silt, correction of soil acidity and subsequent soil nutrient and pest management ensured better crop performance.

There are reports that the productivity levels during 2019-2020 are also on par with post-flood levels though official data is yet to be published. The community resilience development that focussed on an ecosystem-based approach (EBA) through social and knowledge capital built up by state participation has proved to be sustainable.

\subsubsection{Medium- and Long-Term Strategies}

The medium- to long-term measures to build up the resilience measures include flood forecasting based on flood-modelling studies. The main lead for this initiative is under the National Hydrology Project in close coordination with the ongoing interventions under river rejuvenation, lift irrigation stations, regulators and flood bunds in the Kuttanad region (Government of Kerala, 2019). Thus, multisector interventions along with systematic planning are expected to strengthen flood resilience in the region. The Kerala State Planning Board has also recommended a Rs. 2448-crore (USD340 million) special package and the state government has taken the decision to implement the same. The special Kuttanad package aims to improve the sanitation, water supply, flood control, management of water bodies, promotion of organic farming and to ensure responsible tourism and sustainable development.

Community resilience is becoming an effective strategy for enhancing community-level disaster preparedness, response and recovery. It is the ability of communities to withstand hazards and is also intertwined with individual resilience (Norris et al., 2008). Rural agricultural communities are food producers and source of environmental and social functionalities who build resilience through increased robustness and redundancy (Wilson, 2010). Hence, the most effective way to ensure a safe and healthy society is to train and equip them to mitigate and adapt to natural disasters. Capacitating the communities for EBA approaches makes the social system move towards welfare with equity and quality. 


\subsection{State Silence About Water Scarcity in Chittur and Wayanad}

The responses of individuals and communities to stresses differ according to the nature of the climate event (weather extreme or climate change). The response to water scarcity is a slow process wherein the individual/community responses develop slowly, over a period of time depending on the adaptive capacity. Adaptive capacity differs among people, communities and countries across space and time. Community's adaptive capacity is a dynamic function of local processes and conditions, which are influenced by wider socio-economic and political scenarios, and access to resources (Smit \& Wandel, 2006). Population pressure and resource depletion leading to limited access to resources may progressively lessen a system's coping ability, while economic growth and improvements in technology may lead to an increase in community's adaptive capacity (Folke et al., 2002; Smit \& Pilifosova, 2003). Here, we discuss the resilience behaviour in response to water scarcity wherein collective action by farmers and the state's active presence are absent. The padasekhara samitis were historically evolved farmer collectives in Kuttanad rice farming due to the ecosystem peculiarities and political economy of the region. Unlike that situation, such strong and active farmer collectives are not present in Chittur and Wayanad.

The climate change impacts include both slow effects such as the reduced availability of natural resources like water as well as sudden extreme weather events like floods. However, the extreme events get more state attention and intervention compared to the long-term slow and steady adverse effects. This may be due to political reasons as climate extremes get more public attention and the state response is widely acknowledged and appreciated whereas measures against water scarcity issues are often less visible as they are more general in nature.

\subsection{Water Scarcity and Community Responses}

Kerala has been often perceived as a 'water-rich state' with an average annual rainfall of $3000 \mathrm{~mm} / \mathrm{year}$ and a large number of freshwater bodies. Recently, the state has been experiencing more rainfall deficit years and acute water scarcity. With high runoff losses (40\%) and progressively declining groundwater levels, the scarcity is getting intensified. While the agricultural practices and policies support irrigated agriculture, the resource scarcity poses challenges in agricultural production and food security. Agriculture is the major consumer of fresh water resources in the state, as is the case globally. Chittur Block in Palakkad district of Kerala represents the case of increasing water scarcity and farmer responses as it is a predominantly agriculture area situated in the North Eastern side of Kerala. According to the State Ground Water Department, Chittur is a groundwater over-exploited area which faces severe water scarcity, perhaps the worst in the state. 
Wayanad is a hilly, ecologically sensitive agricultural district of Kerala. The region is reported to be experiencing lower rainfall and has had a falling water table, over the years. The main source of irrigation is from open wells and the average depth of open wells in the study area was $10.75 \mathrm{~m}$ whereas the decline in water table was to the tune of 4-5 m during the peak summer season. About $47 \%$ of the sample respondents in a study in Wayanad reported a 75\% deviation in the water table (Rinu, 2012). It is evident that the situation is getting worse, as the deviation was $36.08 \%$ in 2005 and only $6.6 \%$ in 2000 .

The major source of drinking and irrigation water in Kerala is open wells, with a very high well density of 200 wells per $\mathrm{km}^{2}$ in the coastal region, 150 wells per $\mathrm{km}^{2}$ in the midland and 70 wells per sq.km in the high land. As reported in the Wayanad study, the traditional practice was of depending on common wells, ponds or water sources from the neighbourhoods for domestic as well as irrigation purposes. There was a gradual shift from common sources to individually owned sources during a span of 10 years from 2000 . Nearly $84 \%$ of the homesteads own either open wells, tube wells or ponds as compared to the years 2005 and 2000, when it was $79 \%$ and $75 \%$, respectively. In 2000, only $63 \%$ had access to their own open wells and six $\%$ owned tube wells. However, only two-thirds of marginal farmers have their own sources compared to $95 \%$ for both small farmers and large farmers. This implies that the existing inequality in land holdings also leads to inequity in access to groundwater, which in turn further skews the divergence in assets and income distribution.

The farmers' immediate response to the declining water table in their own wells was to deepen them and subsequently, when the wells dried up, to dig new open wells. Chittur area experienced growing levels of water scarcity and severe and recurrent drought during the 2002-2005 period and a majority of the wells dried up. Since then the strategy shifted to digging borewells and later on deepening them. There were instances wherein the farmers used dried up open wells as storage structures for water pumped from borewells and pumping water from these open wells for irrigation (Fig. 8.1). Eventually, these borewells also dry up. The farmer's decision to opt for borewells and competitive well deepening is often influenced by the private borewell operators who extend the services as a package linking with credit support from institutional/non-institutional agencies. As the water scarcity worsens and borewells also dry up, farming activities are adversely affected, and farmers become defaulters. There are informal reports of social and domestic problems and farmer suicides on account of such pressures. Balasubramanian and Saravanakumar (2022, Chap. 10 this volume) document how state policy may itself have triggered such outcomes as adverse incentive emerging from subsiding electricity.

Table 8.3 provides details on various adaptation patterns and the economic costs of each adaptation in the Chittur area obtained/collected through a field survey conducted in 2015. During a span of five years from 2005, only $14 \%$ farmers who owned open well-irrigated farms decided to deepen the existing open wells. This could be done with an investment of USD 51 per farm per year (amortized cost). However, these wells also dried up after 2-3 years. Only $2 \%$ of the farmers dug new open wells at an annual amortized cost of USD 22 per farm. Deepening of existing 


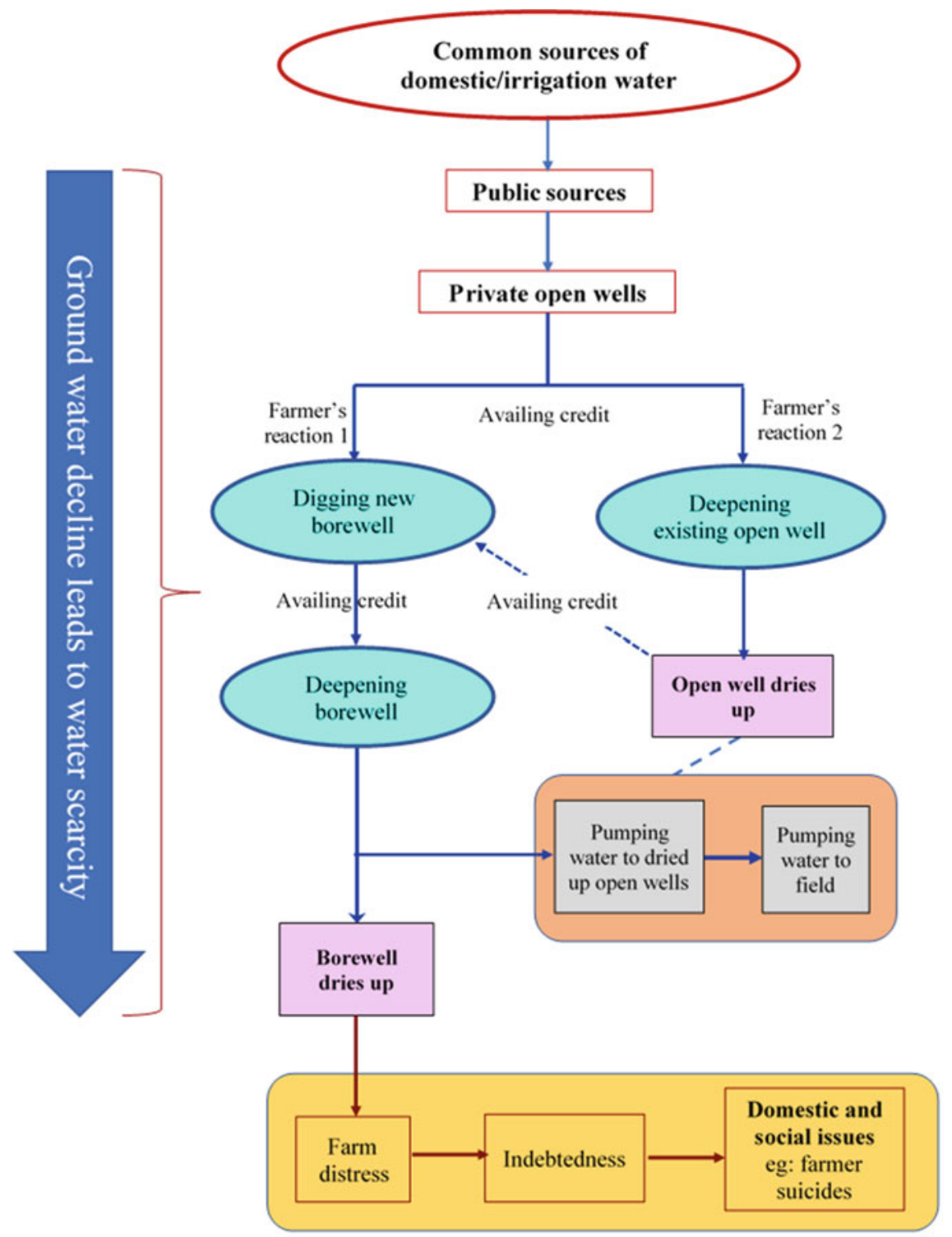

Fig. 8.1 Farmer's reactions to water scarcity. Source Author's compilation

wells was found costlier than digging new open wells, as the existing wells had hard rock layers at deeper levels (Table 8.3).

The majority of the famers (52\%) opted for digging new borewells which irrigated nearly $59 \%$ of cultivated area. The technological advancement in this sector coupled with credit support has facilitated the spread of borewells. Moreover, a large number 
Table 8.3 Adaptation to water scarcity and economic costs of adaptation in Chittur area

\begin{tabular}{l|l|l}
\hline Particulars & $\begin{array}{l}\text { Samples of open well owned } \\
\text { farmers }\end{array}$ & $\begin{array}{l}\text { Samples of borewell owned } \\
\text { farmers }\end{array}$ \\
\hline Existing wells deepening & \multicolumn{2}{l}{} \\
\hline Farmers adoption rate (\%) & 14 & 6 \\
\hline Area benefitted (\%) & 19 & 5 \\
\hline Cost (USD/ha/year) & 32 & 45 \\
\hline Cost (USD/farm/year) & 51 & 48 \\
\hline Digging of new borewells & \multicolumn{2}{|l}{} \\
\hline Farmers adopted (\%) & 52 & 58 \\
\hline Area benefitted (\%) & 59 & 61 \\
\hline Cost (USD/ha/year) & 69 & 116 \\
\hline Cost (USD/farm/year) & 86 & 169 \\
\hline New open wells digging & \multicolumn{2}{|l}{} \\
\hline Farmers adoption rate (\%) & 2 & 0 \\
\hline Area benefitted (\%) & 3 & 0 \\
\hline Cost (USD/ha/year) & 30 & 0 \\
\hline Cost (USD/farm/year) & 22 & 0 \\
\hline
\end{tabular}

Source Seenath (2017)

of private operators who constantly updated the technology prompted the farmers to opt for borewells. Often the borewell operators arranged the institutional or noninstitutional credit support to the farmers. Due to the weak regulatory mechanism by the state, the private borewell operators created an environment for widespread digging of borewells. They facilitated credit, technological and institutional support for digging new borewells.

Though there are strict guidelines and licensing systems for borewell digging, the implementation is not strict due to poor monitoring and governance. The absence of farmer collectives leads to actions based on private motives, often at competitive levels.

A farmer invests an average amount of 169 USD per year (amortized) for digging a new borewell (average depth of $177 \mathrm{~m}$ ), mainly with credit support. Though the Central Ground Water Board (2013) has advised that the maximum feasible depth of borewells in Chittur region as $150 \mathrm{~m}$ below ground level (mbgl), the depth of borewells was increasing at an annual rate of $2.9 \mathrm{~m} /$ year. In 2000, the average depth of borewells in Chittur region was $140 \mathrm{mbgl}$ which had increased to $180 \mathrm{mbgl}$ during 2014. Furthermore, the water reserve for open wells is unconfined aquifers, while borewells depend on confined aquifers. The recharge of confined aquifers takes many years (while unconfined aquifers get recharged at a faster rates) and hence resource replenishment is not in tune with extraction rates. Thus, intensive usage of water from borewells may lead to drying up of borewells because of the quicker extraction and slow recharge. This may further intensify water scarcity and thus proves to be 
unsustainable. Digging new wells and competitive deepening of existing open wells to adapt to water scarcity are common among the farmers across India (Shaheen \& Shiyani, 2005).

Apart from deepening, the water extraction methods have also been modernized, viz. centrifugal, submersible and compressor pumps fitted with electric motors. Except a few (6\%), all the farms have either replaced the conventional centrifugal pumps with new ones or upgraded to submersible pumps. Submersible pumps are energy efficient and even suitable for summer months, if the wells have adequate water to submerge the motor and pump set. In the case of borewells with low water yield, compressor pump is appropriate. In Chittur, the wells are fitted mostly with compressor pumps. Most farms (72\%) in the area used compressor pumps with valve systems with switching over facility between open well and borewell. Usually, the farmers resorted to continuous pumping for 7-18 h during early summer months and stored the water in existing open wells. Subsequently, water is pumped from the open wells. The average pumping time in farms with both open and borewells was $1286.8 \mathrm{~h} / \mathrm{ha} /$ year. This was three times greater than that of the pumping time in farms with only open wells. This system though exploitative and energy intensive is not reflected in the private cost accounting, as fuel charges are fully subsidized. These case studies highlight the unscientific and uneconomical practices followed by individual farmers as well as the weak government regulatory mechanism to control the exploitative responses of the individuals towards common property rights (CPRs) of water. Poor state interventions, absence of collective action and faulty policies have led to financially weak, unsustainable and resource-depleting practices. There are clear evidences of rigorous groundwater extraction from other Indian states like Punjab, Haryana and Uttar Pradesh, which is facilitated by the public policies (energy and chemical input subsidies) and green revolution technologies (Chand and Parappurath 2011; Jeevandas et al., 2008).

While the consumption of water is on the increase, the efforts to conserve and improve the supply are rather limited. Water conservation structures are one of the solutions to improve groundwater availability by enhancing recharge. However, lowcost conservation methods such as conservation pits and water harvesting tanks were adopted by only less than $10 \%$ farmers. Those who followed the practice failed to follow the scientific approach as well. These water conservation techniques are slow to show the results, though they are very cost effective (USD61 and USD89 per ha per year). Burying of coconut husk and mulching with coconut leaves were also not very popular, despite its proven results. The time lag in realizing the returns and sensitivity to discount rates limit the level of adoption of such measures (Pande et al., 2011). The main reasons for low adoption of private conservation investments are incomplete property rights and the externalities (high cost of exclusion and nonrivalry) associated with public goods. Leach et al. (1999) have argued that stewardship over natural resources is the state's responsibility and conservation measures could be initiated by the state. This view was shared by the respondents as well. These measures are not promoted by private agencies because of low profitability which has also contributed to limited adoption. 
At the same time, roof water harvesting, adopted by $14 \%$, was installed with technical and financial support from grass-roots-level government organizations and the National Bank for Agricultural and Rural Development (NABARD) at a cost of USD34/unit/year with 50\% subsidy. The presence of the public sector thus facilitates adoption of natural resource-based practices that ensures sustainability. Thus, it is very clear that collective action with support from government and other public sector organizations contributes to resilience strategies which are sustainable and efficient. Behavioural responses of communities to resource scarcity and resilience are largely governed by the technical and financial backing from the public sector. Thus, in the absence of collective action nurtured by the state, the individual actions are resource depleting and exploitative in nature. Poor governance and monitoring lead to the operation of private market players who prompt resource-depleting unsustainable consumption practices. It is also noticed that state's interventions in addressing such issues (resource conservation) where results are visible only slowly and steadily are rather limited. This may be due to political reasons as well. While sudden and extreme weather events attract public attention, the climate change impacts of longterm nature do not attract massive public attention. The situation is further aggravated by absence of bargaining power, as collectives are not present.

\subsection{Conclusions}

Community resilience denotes the sustained capability of a community to employ available resources to respond to, withstand, and recover from the adverse effects of any disquiets. This chapter gives a clear overview on the importance of state interventions and regulatory mechanisms to ensure sustainability and judicious utilization of common property resources in individual responses to different stress situations (flood and drought). The first case study in Kuttanad flood region demonstrated how public investments, technological interventions and collective action built up the resilience to disasters among farmers that could lead to bumper harvest and sustainable farming culture.

The cases of Chittur and Wayanad areas depict adoption of supply-driven strategies to improve resource availability which were mainly exploitative in nature, viz. borewell digging, deepening and intensive extraction. This is perhaps due to the absence of public sector intervention and the exploitative approach of private market operators. At the same time, the conservation approach was found to be rather poor. The respondent's expectation of the state's role in resource conservation also restricts their conservation behaviour. A similar situation in Wayanad district shows an increased level of privatization of common property resources (water) with more farmers ensuring their own sources for water rather than traditional common sources. This has also led to widening social inequalities as the existing inequality in land holdings leads to an inequity in access to groundwater, which in turn widens the skewness in assets and income distribution where the state has chosen not to intervene. 
The role of the state in capacitating and enhancing the preparedness and postdisaster management through policy shifts, capacity building and facilitating collective action is underlined. At the same time, the responses of the political system to climate risks are found to vary according to the nature of the risk. The catastrophes (floods) and pandemics trigger immediate and effective action while climate change-induced slow impacts (water scarcity) do not attract the same approach. Capacitating the communities on EBA through active state participation facilitates collective action that ensures sustainable outcomes.

\section{References}

Ahmed, A. (2022). Autonomous adaptation to flooding by farmers in Pakistan. In A. K. E. Haque, P. Mukhopadhyay, M. Nepal, \& M. R. Shammin (Eds.), Climate change and community resilience: Insights from South Asia (pp. 101-112). Springer.

Balasubramanian, R., \& Saravanakumar, V. (2022). Climate sensitivity of groundwater systems in South India: Does it matter for agricultural income? In A. K. E. Haque, P. Mukhopadhyay, M. Nepal, \& M. R. Shammin (Eds.), Climate change and community resilience: Insights from South Asia (pp. 143-156). Springer.

Bari, E., Haque, A. K. E., \& Khan, Z. K. (2022). Local strategies to build climate resilient communities in Bangladesh. In A. K. E. Haque, P. Mukhopadhyay, M. Nepal, \& M. R. Shammin (Eds.), Climate change and community resilience: Insights from South Asia (pp. 175-189). Springer.

Burton, C. G. (2015). A validation of metrics for community resilience to natural hazards and disasters using the recovery from Hurricane Katrina as a case study. Annals of the Association of American Geographers, 105(1), 67-86. https://doi.org/10.1080/00045608.2014.960039

Central Ground Water Board. (2013). Annual report 2012-2013. Ministry of Water Resources, New Delhi.

Chand, R., \& Parappurathu, S. (2011). Historical and spatial trends in agriculture: Growth analysis at national and state level in India. In IGIDR Proceeding/Projects Series no. PP-069-3b. November, 10-11 2011, India International Centre (on-line). Available at http://www.igidr.ac.in/newspdf/sri jit/PP-069-03b.pdf. Accessed November 30, 2020.

Cimellaro, G. P., Renschler, C., Reinhorn, A. M., \& Arendt, L. (2016). PEOPLES: A framework for evaluating resilience. Journal of Structural Engineering, 142(10), 4016063. https://doi.org/ 10.1061/(ASCE)ST.1943-541X.0001514

Colls, A., Ash, N., \& Ikkala, N. (2009). Ecosystem-based adaptation: A natural response to climate change. In International Union for conservation of nature and natural resources Switzerland. Available at https://www.iucn.org/content/ecosystem-based-adaptation-a-natural-responseclimate-change. Accessed November 30, 2020.

Cutter, S. (2016). Social vulnerability and community resilience measurement and tools. University of South Carolina.

Folke, C., Carpenter, S., Elmqvist, T., Gunderson, L., Holling, C.S., \& Walker, B. (2002). Resilience and sustainable development: Building adaptive capacity in a world of transformation. AMBIO: A Journal of the Human Environment, 31(5), 437-440. https://doi.org/10.1579/0044-7447-31. 5.437

Government of Kerala. (2018). United Nations, Asian Development Bank, The World Bank, European Union Civil Protection and Humanitarian Aid, Kerala Post Disaster Needs Assessment Floods and Landslides_August 2018, Government of Kerala. Available at https://rebuild.kerala. gov.in/reports/PDNA_Kerala_India.pdf

Government of Kerala. (2019). Rebuild Kerala, development programme. Government of Kerala. 
Hoque, M. Z., Cui, S., Lilai, X., Islam, I., Ali, G., \& Tang, J. (2019). Resilience of coastal communities to climate change in Bangladesh: Research gaps and future directions. Watershed Ecology and the Environment, 1, 42-56. https://doi.org/10.1016/j.wsee.2019.10.001

Intergovernmental Panel on Climate Change. (2012). Special Report on Managing the Risks of Extreme Events and Disasters to Advance Climate Change Adaptation. In C. B. Field, V. Barros, T. F. Stocker, D. Qin, D. J. Dokken, K. L. Ebi, M. D. Mastrandrea, K. J. Mach, G. K. Plattner, S. K. Allen, M. Tignor, \& P. M. Midgley (Eds.), A special report of working groups I and II of the intergovernmental panel on climate change (pp. 582). Cambridge University Press.

Jeevandas, A., Singh, R. P., \& Kumar, R. (2008). Concerns of groundwater depletion and irrigation efficiency in Punjab agriculture: A micro-level study. Agricultural Economics Research Review, 21, 191-199.

Kattel, R. R., \& Nepal, M. (2021). Rainwater harvesting and rural livelihoods in Nepal. In A. K. E. Haque, P. Mukhopadhyay, M. Nepal, \& M. R. Shammin (Eds.), Climate change and community resilience: Insights from South Asia (pp. 159-173). Springer.

Kerala Agricultural University. (2019). Report of soil analysis in Alappuzha and Kottayam districts. Prepared by RARS, Kumarakom. 2019. Thrissur, Kerala 1:3.

Koohafkan, P., \& Altieri, M. A. (2010). Globally important agricultural heritage systems: A legacy for the future. UN-FAO.

Leach, M., Mearns, R., \& Scoones, I. (1999). Environmental entitlements: Dynamics and institutions in community-based natural resource management. World Development, 27(2), 225-247. https:// doi.org/10.1016/S0305-750X(98)00141-7

Munang, R., Thiaw, I., Alverson, K., Mumba, M., Liu, J., \& Rivington, M. (2013). Climate change and Ecosystem-based Adaptation: A new pragmatic approach to buffering climate change impacts. Current Opinion in Environmental Sustainability, 5(1), 67-71. https://doi.org/10.1016/ j.cosust.2012.12.001

Norris, F. H., Sherrieb, K., Galea, S., \& Pfefferbaum, B. (2008). Capacities that promote community resilience: can we assess them? Paper presented at the 2nd annual Department of Homeland Security University Network Summit, Washington, DC. www.orau.gov/dhsresummit08/presen tations/Mar20/Norris.pdf

Pande, V. C., Kurothe, R. S., Singh, H. B., \& Tiwari, S. P. (2011). Incentives for soil and water conservation on farm in Ravines of Gujarat: Policy implications for future adoption. Agricultural Economics Research Review, 24(1), 109-118.

Rinu, T. V. (2012). Socio economic vulnerability and adaptive strategies to environmental risk: A case of water scarcity in agriculture. MSc (Ag) thesis, Kerala Agricultural University.

Seenath, P. (2017). Groundwater irrigation: Management, adaptation and economic costs under declining resource conditions. Ph.D. Thesis, Kerala Agricultural University.

Shaheen, F. A., \& Shiyani, R. L. (2005). Water use efficiency and externality in groundwater exploited and energy subsidised regime. Indian Journal of Agricultural Economics, 60(3), 445457.

Smit, B., \& Wandel, J. (2006). Adaptation, adaptive capacity and vulnerability. Global Environmental Change, 16(3), 282-292. https://doi.org/10.1016/j.gloenvcha.2006.03.008

Smit, B., \& Pilifosova, O. (2003). From adaptation to adaptive capacity and vulnerability reduction. In J. B. Smith, R. J. T. Klein, \& S. Huq (Eds.), Climate change (p. 158p). Imperial College Press.

Wilson, G. (2010). Multifunctional "quality" and rural community resilience. Transactions of the Institute of British Geographers, 8, 35(3), 364-381. Available at http://www.jstor.org/stable/408 90993. Accessed November 30, 2020. 
Open Access This chapter is licensed under the terms of the Creative Commons AttributionNonCommercial-NoDerivatives 4.0 International License (http://creativecommons.org/licenses/bync-nd/4.0/), which permits any noncommercial use, sharing, distribution and reproduction in any medium or format, as long as you give appropriate credit to the original author(s) and the source, provide a link to the Creative Commons licence and indicate if you modified the licensed material. You do not have permission under this licence to share adapted material derived from this chapter or parts of it.

The images or other third party material in this chapter are included in the chapter's Creative Commons licence, unless indicated otherwise in a credit line to the material. If material is not included in the chapter's Creative Commons licence and your intended use is not permitted by statutory regulation or exceeds the permitted use, you will need to obtain permission directly from the copyright holder.

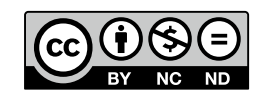

